\title{
BMJ Open Do specific parenting practices and related parental self-efficacy associate with physical activity and screen time among primary schoolchildren? A cross-sectional study in Belgium
}

\author{
Sara De Lepeleere, Ilse De Bourdeaudhuij, Greet Cardon, Maïté Verloigne
}

To cite: De Lepeleere S, De Bourdeaudhuij I, Cardon G, et al. Do specific parenting practices and related parental self-efficacy associate with physical activity and screen time among primary schoolchildren?

A cross-sectional study in Belgium BMJ Open 2015;5: e007209. doi:10.1136/ bmjopen-2014-007209

\section{- Prepublication history} and additional material is available. To view please visit the journal (http://dx.doi.org/ 10.1136/bmjopen-2014007209).

Received 14 November 2014 Revised 17 July 2015 Accepted 18 August 2015

CrossMark

Department of Movement and Sport Sciences, Ghent University, Ghent, Belgium

Correspondence to Sara De Lepeleere; Sara.DeLepeleere@UGent.be

\section{ABSTRACT}

Objectives: To assess the association between specific parenting practices and related parental selfefficacy with children's physical activity (PA) and screen time. Parental body mass index (BMI), family socioeconomic status (SES), and child's age and gender were examined as possible influencing factors.

Design: Cross-sectional.

Setting: January 2014, Flanders (Belgium). Participants: 207 parents ( $87.4 \%$ mothers) of children aged $6-12$ years.

Outcome measures: Specific parenting practices, related parental self-efficacy, and children's PA and screen time.

Results: The majority of investigated parenting practices and related parental self-efficacy were not significantly associated with children's PA or screen time. However, children were more physically active if sports equipment was available at home $(p<0.10)$ and if parents did not find it difficult to motivate their child to be physically active $(p<0.05)$. Children had a lower screen time if parents limited their own gaming $(p<0.01)$. The associations between parenting practices and related parental self-efficacy with children's PA or screen time were significant for parents with a normal BMI, for medium-high SES families and for parents of younger children. Furthermore, the association between the parenting relating factors and children's PA and screen time differed for boys and girls.

Conclusions: In contrast to what we expected, the findings of the current study show that only a very few specific parenting practices and related parental selfefficacy were associated with children's PA and screen time. It was expected that parental self-efficacy would play a more important role. This can be due to the fact that parental self-efficacy was already high in this group of parents. Therefore, it is possible that parents do not realise how difficult it is to perform certain parenting practices until they are faced with it in an intervention.

Trial registration number: EC/2012/317.

\section{Strengths and limitations of this study}

- Combining both specific parenting practices and related parental self-efficacy for each specific parenting practice.

- Self-report questionnaires: social desirability bias.

- Cross-sectional study: no statements about causality.

- Eighty-eight per cent of participants female $+84 \%$ of participants of medium-high SES: selection bias.

\section{BACKGROUND}

The increasing prevalence of childhood overweight and obesity worldwide is an important health concern. ${ }^{12}$ Besides an unhealthy diet, insufficient physical activity (PA) and too much sedentary behaviour play a major role in the development of overweight and obesity. ${ }^{3-5}$ Worldwide research has indicated that about $40-80 \%$ of children do not achieve the guidelines of at least $60 \mathrm{~min}$ of moderate-to-vigorous PA on most days of the week. $^{6-8}$ The ENERGY project (conducted in seven European countries among children aged $10-12$ years) showed that $83.2 \%$ of the European boys and $95.4 \%$ of the girls were not sufficiently physically active. ${ }^{9}$ For sedentary behaviours, Tremblay et al conducted a systematic review which presented available evidence for minimal and optimal thresholds for daily sedentary time in children and youth. The review included 232 studies from 39 different countries and concluded that daily screen time (TV and computer activities combined) should be limited to a maximum of $2 \mathrm{~h}$ /day. ${ }^{10}$ However, the ENERGY project showed that European children spent on average more than $2 \mathrm{~h}$ /day on screen time. ${ }^{11}$ 
Therefore, it is important to develop interventions which stimulate PA as well as limit screen time in primary schoolchildren.

Results from cross-sectional and longitudinal studies ${ }^{12-15}$ over the past decade illustrate that parents play a major role in the development of health behaviours such as PA and screen-time behaviour of their primary schoolchildren. ${ }^{16}$ Parents can influence their children's personal and behavioural determinants by shaping their attitudes and social norms and by enhancing their children's selfefficacy in exhibiting a healthy lifestyle. ${ }^{17-19}$ Additionally, specific parenting practices such as providing sports equipment to be physically active, ${ }^{20}$ being physically active together with your child, ${ }^{21}$ parental rules $^{21}$ and parental levels of PA and screen time (modelling) ${ }^{22}$ are influential in their children's development of lifelong habits that contribute to normal weight or to overweight and obesity. It is therefore important that parents are made aware of their important influencing role. However, parents are sometimes aware of which parenting practices they should apply but experience low feelings of competence to effectively adopt those parenting practices. ${ }^{23}$ The expectation parents (or other caregivers) hold about their ability to perform effective parenting practices $^{24}$ is defined as parental self-efficacy. Enhancing parental self-efficacy concerning parenting practices might be an important step in effectively adopting these parenting practices. Some parents may need help in learning how to increase their use of effective, as well as decrease their use of ineffective, parenting practices. ${ }^{23}$

Currently, multiple intervention studies incorporate a random mix of parenting practices to promote PA or to decrease screen time without knowing which parenting practices are most relevant in changing a particular health behaviour of the child. ${ }^{25}{ }^{26}$ Furthermore, to the best of our knowledge, only one study has examined the association between parental self-efficacy and children's $\mathrm{PA}$ and screen time and found that higher parental selfefficacy to limit screen viewing was associated with a $77 \%$ reduction in the likelihood of the child watching $\geq 2 \mathrm{~h}$ of TV per day. ${ }^{27}$ However, the study of Jago et al only investigated parental self-efficacy to limit screen viewing and promote PA of their preschool child and parents' own PA self-efficacy, although there is a broad range of parenting practices.

Therefore, since parental self-efficacy seems to be an important concept in parenting but remains an understudied subject, this study also investigated for every specific parenting practice the corresponding parental self-efficacy.

For future interventions, it is important to know which specific parenting practices and related parental selfefficacy are significantly associated, and which ones are not, with children's PA and screen time. In this way, interventions can teach parents which parenting practices are effective and, even more important, they can show parents how to perform those parenting practices. Thus, the first aim of this study was to examine the association between specific parenting practices and related parental self-efficacy with PA and screen time among primary schoolchildren.

In addition, it is possible that the association between specific parenting practices and related parental selfefficacy and children's PA and screen-time behaviour differs for specific subgroups. In previous studies, it has been shown that parenting practices can differ according to a child's gender, ${ }^{28-31}$ a child's age ${ }^{32}$ and family socioeconomic status (SES). ${ }^{33}$ Furthermore, parental body mass index (BMI) has been associated with children's PA and screen time. ${ }^{34}$ Therefore, the second aim of this study is to investigate the aforementioned associations separately for parents with normal and high BMI, for low and high SES families, for younger and older children, and for boys and girls. This information could be important for future intervention developers to tailor the intervention to a specific subgroup.

\section{METHODS}

\section{Study design and setting}

An online cross-sectional survey on PA and screen time, specific parenting practices and parental self-efficacy was conducted in Flanders (ie, the Dutch-speaking part of Belgium).

\section{Participants and recruitment}

A convenience sample of parents of primary schoolchildren was recruited in different ways. First, principals of 36 primary schools in Flanders were contacted personally by the researchers. In total, 30 schools (83\%) agreed to participate. The only reason to decline was 'not enough time' $(\mathrm{n}=6)$. In November-December 2013, flyers $(n=5077)$ to invite parents to participate were distributed in the participating schools to all children aged 6-12 years to take home. Furthermore, an appeal to participate was spread by (social) media: two Flemish magazines for parents (Klasse' and 'De Gezinsbond) and the Facebook page of EXPOO (an expertise centre for parenting support). Since it is unknown how many parents were reached by the invitation appeals, it is not possible to calculate a reliable response rate. The recruitment of parents was ended by the second week of January 2014. Parents who wanted to participate had to send an email to the researcher. Afterwards, they were sent an information letter which contained information on the goal, the inclusion criteria, the content, the course, the starting and ending procedure, the risks and advantages, and confidentiality of the study. Furthermore, participants were sent the link to the online questionnaire and provided informed consent by returning this online questionnaire. A total of 238 parents agreed to participate, of whom 207 $(87 \%)$ completed the questionnaire. 


\section{Measures}

At the beginning of the questionnaire, it was mentioned that if parents had more than one child in primary school, they could choose for which child they wanted to complete the entire questionnaire. The parental questionnaire assessed demographic variables, specific parenting practices, parental self-efficacy concerning these practices, and the child's PA and screen time.

\section{Demographic variables}

Age and gender of the child, weight and height of both parents, and number of children living in the house were reported in the questionnaire. The reported educational level of the parent who completed the questionnaire was used as a proxy for SES. Low SES was determined as parents having no higher education and medium to high SES as parents having higher education (vocational college, university or postacademic). ${ }^{35}$ Parental BMI (weight/height squared) was calculated from the self-reported height and weight of the father and mother. According to the existing WHO cut-off points, ${ }^{36}$ normal weight was determined as BMI $<25 \mathrm{~kg} / \mathrm{m}^{2}$ and overweight/obesity as BMI $\geq 25 \mathrm{~kg} / \mathrm{m}^{2}$.

\section{Child's PA and screen time}

Levels of PA and screen time were assessed by the questionnaire adopted from the validated Flemish Physical Activity Questionnaire (FPAQ). ${ }^{37}$ The FPAQ is a reliable (intraclass correlation coefficient $=0.70$ ) and valid $(\mathrm{R}=0.78)$ instrument to measure PA and screen time. ${ }^{38}$ Total PA was assessed by adding up minutes spent in active transportation (to school and in leisure time on weekdays and weekend days) and time spent in sports (at school and during leisure time on weekdays and weekend days). Screen time was calculated by adding up minutes spent watching TV (In a normal week, how many hours a day does your child watch TV or DVDs on weekdays/on weekend days?), playing computer games and using game consoles (In a normal week, how many hours a day does your child play games on the computer, Nintendo, PlayStation, iPad or does he/she use chatting facilities such as Facebook, Skype...on weekdays/on weekend days?) on weekdays and weekend days. To obtain a total sum score for PA and screen time, firstly the average number of minutes spent on PA or screen time on a weekday were multiplied by five and the average day of minutes spent on a weekend day were multiplied by two. Secondly, the resulting numbers were counted up to acquire the weekly score for PA and screen time.

\section{Specific parenting practices}

The specific parenting practice items were based on the validated Parental Support For Physical Activity Scale ${ }^{16}$ and Parenting Strategies for Eating and Activity Scale. ${ }^{39}$ Most items were assessed on a two-point scale (disagree-agree) or a five-point Likert scale ranging from 'never' to 'always', which were treated as interval data. For most questions, 'Not Applicable' was an alternative answer category of which the results were set as missing values. Availability of TV, pc and game consoles was questioned on a six-point scale (ranging from 0 to more than 4), and the availability of different kinds of sports equipment (eg, bike, tennis or badminton racket, ball) on a two-point scale (yes-no). A sum score of the different kinds of sports equipment was made to obtain the total availability of sports equipment. Online supplementary table S1 shows the exact formulation and descriptive statistics of the questionnaire items for PA and screen time.

\section{Parental self-efficacy concerning the specific parenting practices}

The parental self-efficacy questions were created analogous to the questions on the specific parenting practices, and were based on the translation of the GEMS (Girls Health Enrichment Multisite Study) questionnaire, ${ }^{40}$ the validated questionnaire of parental self-efficacy for enhancing healthy lifestyles in their children ${ }^{41}$ and section L of the Aventuras Para Ninos parent survey. ${ }^{42}$ The items were assessed by using a five-point answering format ranging from 'completely disagree' to 'completely agree' (see online supplementary table S1). These items were recoded to obtain a higher score when parents had a higher self-efficacy.

\section{Data analysis}

Preliminary analyses consisted of descriptive statistics of sample characteristics and checking the normality of key variables. Since the variable outcomes of PA and screen time were skewed, square root transformations were used to obtain variables with a normal distribution.

To examine associations between parenting practices related to PA and screen time or parental self-efficacy concerning these practices and PA and screen time, single linear regressions were conducted in a first step. In case of significance, the parenting-related factor was included in a multiple linear regression model, preceded by bivariate correlations to check for intercorrelation among the selected parenting-related factors. When the correlation coefficient was higher than 0.60 , only the parenting-related factor with the highest bivariate correlation with PA or screen time was included. Parental BMI, family SES, child's age and child's gender were entered as covariates in this model. To examine the possible influencing role of parental BMI, family SES, child's age and child's gender, the multiple linear regression model was conducted separately for normal weight families versus families with at least one parent with overweight/obesity, low SES versus medium-high SES families, younger children (6-8 years) versus older children (9-12 years) and girls versus boys. p Values $<0.05$ were considered significant; $p$ values $\geq 0.05$ and $<0.10$ were considered borderline significant. Standardised $\beta$-values were reported. All analyses were conducted using SPSS (SPSS V.20.0, IBM Corp, Armonk, New York, USA; 2011). 


\section{RESULTS}

\section{Study characteristics}

An overview of the descriptive characteristics is given in table 1. In total, 207 parents with a mean age of 40.2 \pm 5.0 years completed the questionnaire. Parents who completed the survey were predominantly mothers $(87.4 \%)$. The majority $(83.5 \%)$ of participating parents had a medium-high SES. Normal weight was found in $68.2 \%$ of the mothers and $56.2 \%$ of the fathers. The mean number of children per family was two. Slightly more than half of the questionnaires $(51.7 \%)$ were filled out for boys, and the mean age of the children was 9.4 \pm 1.6 years. Overall, the children's mean PA level was 51 $\pm 31 \mathrm{~min} /$ day and children spent on average $2.2 \pm 1.9 \mathrm{~h} /$ day on screen time.

\section{Physical activity}

In the overall sample, as shown in table 2, children were more physically active when sports equipment was available at home $(\mathrm{p}=0.06)$ and when parents did not find it difficult to motivate their child to be physically active $(\mathrm{p}=0.04)$. This model of parenting practices explained $16.1 \%$ of the variance in children's PA.

\begin{tabular}{|c|c|}
\hline Participants (n=207) & $\begin{array}{l}\text { Mean }( \pm S D) \\
\text { or percentage }\end{array}$ \\
\hline $\begin{array}{l}\text { Age of person who completed the } \\
\text { questionnaire }\end{array}$ & $40.2( \pm 5.0)$ years \\
\hline \multicolumn{2}{|c|}{ Person who completed the questionnaire } \\
\hline Mother & 87.4 \\
\hline Father & 10.7 \\
\hline Adoption mother & 1.0 \\
\hline Step mother & 0.5 \\
\hline Grandfather & 0.5 \\
\hline \multicolumn{2}{|l|}{ SES of family } \\
\hline Low & 16.5 \\
\hline Medium-high & 83.5 \\
\hline \multicolumn{2}{|l|}{ BMI class of mother } \\
\hline Underweight & 2.1 \\
\hline Normal weight & 68.2 \\
\hline Overweight & 20.5 \\
\hline Obese & 9.2 \\
\hline \multicolumn{2}{|l|}{ BMI class of father } \\
\hline Underweight & 1.1 \\
\hline Normal weight & 56.2 \\
\hline Overweight & 37.3 \\
\hline Obese & 5.4 \\
\hline Number of children per family & 2 (range $1-5$ ) \\
\hline \multicolumn{2}{|c|}{$\begin{array}{l}\text { Gender of the child for whom the questionnaire was filled } \\
\text { out }\end{array}$} \\
\hline Boy & 51.7 \\
\hline Girl & 48.3 \\
\hline $\begin{array}{l}\text { Age of the child for whom the } \\
\text { questionnaire was filled out }\end{array}$ & $9.4( \pm 1.6)$ years \\
\hline Physical activity of child & $51( \pm 31)$ minutes/day \\
\hline Screen time child & $2.2( \pm 1.9)$ hour/day \\
\hline
\end{tabular}

When only including the significant variables in the analysis, the model explained $10.8 \%$ of the variance in children's PA.

When parents had a normal BMI, children were more physically active (borderline) when parents did not find it difficult to be physically active themselves $(p=0.07)$. In medium-high SES families, children were more physically active when sports equipment was available $(\mathrm{p}=0.02)$ and when parents did not find it difficult to be physically active themselves $(p=0.03)$. Younger children were more physically active when parents did not find it difficult to motivate their child to be physically active $(\mathrm{p}=0.02)$, whereas older children were more physically active (borderline) when sports equipment was available $(\mathrm{p}=0.09)$ and when parents did not find it difficult to be physically active themselves $(\mathrm{p}=0.07)$. Girls were more physically active when sports equipment was available $(p=0.05)$, and when parents did not find it difficult to be physically active themselves $(p=0.02)$ and to motivate their child to be physically active $(\mathrm{p}=0.04$; table 3 ).

\section{Screen time}

In the total sample, a significant negative association was found between 'limiting your own gaming (modelling for games)' ( $p=0.01)$ and children's screen time (table 2$)$. When parents limited their own gaming, children had a lower screen time. This model of parenting practices explained $48.3 \%$ of the variance in children's screen time. When only including the significant variable in the analysis, the model explained $24.0 \%$ of the variance in children's screen time.

When parents had a normal BMI, children had a higher screen time (borderline) if more TVs were available at home $(\mathrm{p}=0.08)$ and a lower screen time if parents followed up their rules about gaming $(p=0.02)$ and limited their own gaming $(\mathrm{p}=0.03)$. Boys had a lower screen time if parents let their child ask for permission to watch TV $(p=0.03)$, if parents followed up their rules about gaming $(p=0.01)$ and if they limited their own gaming $(p=0.01)$. Since the number of participants in the analyses for screen time with family SES and child's age was too small, the influencing role of these factors could not be investigated (table 3).

\section{DISCUSSION}

The results showed that only a very few parenting-related factors were significantly associated with children's PA or screen time: Children were more physically active when sports equipment was available at home and when parents had more self-efficacy to motivate their child to be physically active. When parents limited their own gaming, their child had a lower screen time. However, it has to be stressed that the model for screen time explains a lot of the variation in screen time, which might imply that the included parenting practices and parental self-efficacy play an important role in the screen time of the child. 
Table 2 Associations between parenting practices, related self-efficacy, and children's PA and screen time

\begin{tabular}{|c|c|c|c|c|}
\hline Full model & $\mathbf{N}$ & Adjusted $\mathbf{R}^{2}$ & $\mathbf{F}$ & p Value \\
\hline \multicolumn{5}{|l|}{ Outcome variable: physical activity (minutes/day) } \\
\hline & 170 & 0.161 & 3.942 & $<0.001$ \\
\hline & & $\boldsymbol{\beta}$ & $95 \% \mathrm{Cl}$ & p Value \\
\hline \multicolumn{5}{|l|}{ Explanatory variables } \\
\hline Family SES & & -0.10 & $(-0.59$ to 40$)$ & 0.20 \\
\hline BMI of mother & & 0.01 & $(-0.18$ to 19$)$ & 0.91 \\
\hline BMI of father & & -0.01 & $(-0.25$ to 22$)$ & 0.88 \\
\hline Child's age & & 0.15 & $(-0.33$ to 63$)$ & 0.05 \\
\hline Child's gender & & 0.11 & $(-1.34$ to 1.56$)$ & 0.14 \\
\hline Availability of sports equipment & & 0.14 & $(-0.50$ to 78$)$ & 0.06 \\
\hline SE for monitoring PA & & 0.07 & $(-0.67$ to 80$)$ & 0.42 \\
\hline SE for modelling PA & & 0.15 & $(-0.50$ to 79$)$ & 0.11 \\
\hline SE for motivating PA & & 0.18 & $(-0.63$ to -1.00$)$ & 0.04 \\
\hline SE for giving PA choice & & 0.09 & $(-0.85$ to 1.02$)$ & 0.27 \\
\hline SE for involving PA & & -0.00 & $(-0.71$ to 70$)$ & 0.97 \\
\hline \multicolumn{5}{|l|}{ Outcome variable: screen-time (minutes/day) } \\
\hline Full model & 50 & 0.483 & 4.047 & $<0.001$ \\
\hline \multicolumn{5}{|l|}{ Explanatory variables } \\
\hline Family SES & & -0.16 & $(-1.40$ to 1.09$)$ & 0.19 \\
\hline BMI of mother & & 0.17 & $(-0.27$ to 62$)$ & 0.19 \\
\hline BMI of father & & 0.06 & $(-0.56$ to 69$)$ & 0.63 \\
\hline Child's age & & -0.16 & $(-1.56$ to 1.23$)$ & 0.21 \\
\hline Child's gender & & 0.04 & $(-4.37$ to 4.44$)$ & 0.78 \\
\hline Availability of TV & & -0.03 & $(-2.31$ to 2.27$)$ & 0.81 \\
\hline Availability of game consoles & & 0.16 & $(-1.48$ to 1.79$)$ & 0.17 \\
\hline Permission to watch TV & & -0.20 & $(-7.54$ to 7.14$)$ & 0.15 \\
\hline Being consistent about TV & & -0.09 & $(-4.65$ to 4.48$)$ & 0.57 \\
\hline Being consistent about games & & -0.27 & $(-4.06$ to 3.53$)$ & 0.14 \\
\hline Monitoring of TV & & -0.18 & $(-2.15$ to 1.79$)$ & 0.16 \\
\hline Modelling for games & & -0.40 & $(-2.49$ to 1.69$)$ & 0.01 \\
\hline Letting your child choose him/herself how long he/she can play games & & 0.03 & $(-3.68$ to 3.74$)$ & 0.83 \\
\hline SE for monitoring TV & & 0.01 & $(-2.53$ to 2.54$)$ & 0.96 \\
\hline SE for motivating games & & -0.01 & $(-2.38$ to 2.36$)$ & 0.94 \\
\hline
\end{tabular}

It was expected that parental self-efficacy would play a more important role. This can be due to the high values of self-efficacy in this group of parents which could imply that parents do not find it difficult to perform these parenting practices. It is possible that parents do not realise how difficult it is to perform certain parenting practices until they are faced with it in an intervention. A similar finding was found in an intervention study to decrease sedentary time in children, conducted within the framework of the ENERGY project. It was found that children's self-efficacy regarding TV time declined after the intervention was conducted, possibly because the intervention triggered greater awareness of, for example, how hard it really is to not watch TV/DVD. ${ }^{43}$

Regarding specific parenting practices, only the availability of sports equipment and limited parental gaming (modelling) were significantly related to children's PA and screen time. These results are in line with previous research: in the review of Verloigne $e t a l^{21}$ it was found that parental logistic support was one of the most important positive correlates of $\mathrm{PA}$ and that parental sedentary time had a positive association with screen time. Furthermore, the study of Jago $e t a l^{27}$ also found that parental TV viewing influences children's screen time. However, it has to be acknowledged that the study of Jago et al investigated very specific parenting-related factors (eg, availability of different sport equipment) instead of more general parenting-related factors (eg, logistic support). Consequently, future interventions in a general population of parents may promote the availability of sports equipment at home and limited gaming of parents. Furthermore, parents might learn how they can motivate their child to be physically active (eg, by giving positive feedback or by letting him/her choose between different kinds of PA), which might enhance parental self-efficacy concerning motivating for PA and finally may lead to more PA for their child. However, it must be kept in mind that our study findings are based on crosssectional results, suggesting that no causal inferences can be made. 
Table 3 Associations between parenting practices, related self-efficacy, and children's PA and screen time stratified for parental BMI, family SES, child's age and child's gender

\begin{tabular}{|c|c|c|c|c|c|c|c|c|}
\hline & \multicolumn{4}{|c|}{ Normal BMI } & \multicolumn{4}{|c|}{ One or both parents with high BMI } \\
\hline & $\mathbf{N}$ & $\begin{array}{l}\text { Adjusted } \\
\mathbf{R}^{2}\end{array}$ & $\mathbf{F}$ & p-value & $\mathbf{N}$ & $\begin{array}{l}\text { Adjustec } \\
\mathbf{R}^{2}\end{array}$ & $\mathbf{F}$ & p Value \\
\hline \multicolumn{9}{|c|}{ Outcome variable: physical activity (minutes/day) } \\
\hline \multirow[t]{2}{*}{ Full model } & 78 & 0.167 & 2.714 & 0.009 & 92 & 0.122 & 2.401 & 0.018 \\
\hline & & $\boldsymbol{\beta}$ & $95 \% \mathrm{Cl}$ & p Value & & $\boldsymbol{\beta}$ & $95 \% \mathrm{Cl}$ & p Value \\
\hline \multicolumn{9}{|l|}{ Explanatory variables } \\
\hline Family SES & & -0.08 & $(-0.89$ to 74$)$ & 0.47 & & -0.12 & $(-0.75$ to 51$)$ & 0.25 \\
\hline Child's age & & 0.17 & $(-0.63$ to 92$)$ & 0.23 & & 0.18 & $(-0.49$ to 84$)$ & 0.10 \\
\hline Child's gender & & 0.18 & $(-2.08$ to 2.43$)$ & 0.11 & & 0.04 & $(-1.93$ to 2.01$)$ & 0.70 \\
\hline Availability of sports equipment & & 0.11 & $(-1.07$ to 1.29$)$ & 0.36 & & 0.18 & $(-0.77$ to 1.12$)$ & 0.11 \\
\hline SE for monitoring PA & & 0.11 & $(-1.03$ to 1.26$)$ & 0.35 & & -0.01 & $(-0.98$ to 97$)$ & 0.96 \\
\hline SE for modelling PA & & 0.25 & $(-0.76$ to 1.25$)$ & 0.07 & & 0.05 & $(-0.85$ to 95$)$ & 0.70 \\
\hline SE for motivating PA & & 0.21 & $(-1.15$ to 1.57$)$ & 0.10 & & 0.15 & $(-0.90$ to 1.20$)$ & 0.23 \\
\hline SE for giving PA choice & & 0.08 & $(-1.61$ to 1.77$)$ & 0.51 & & 0.07 & $(-1.10$ to 1.24$)$ & 0.52 \\
\hline SE for involving PA & & -0.06 & $(-1.10$ to 99$)$ & 0.67 & & 0.10 & $(-0.91$ to 1.10$)$ & 0.46 \\
\hline \multicolumn{9}{|c|}{ Outcome variable: screen time (minutes/day) } \\
\hline Full model & 23 & 0.375 & 2.015 & 0.148 & 27 & 0.478 & 2.834 & 0.036 \\
\hline \multicolumn{9}{|l|}{ Explanatory variables } \\
\hline Family SES & & -0.05 & $(-1.86$ to 1.75$)$ & 0.79 & & -0.26 & $(-2.33$ to 1.82$)$ & 0.18 \\
\hline Child's age & & -0.53 & $(-3.35$ to 2.29$)$ & 0.20 & & -0.11 & $(-2.31$ to 2.10$)$ & 0.55 \\
\hline Child's gender & & -0.19 & $(-8.39$ to 8.01$)$ & 0.54 & & -0.14 & $(-8.67$ to 8.39$)$ & 0.53 \\
\hline Availability of TV & & -0.71 & $(-8.35$ to 6.93$)$ & 0.08 & & 0.20 & $(-4.89$ to 5.30$)$ & 0.37 \\
\hline Availability of game consoles & & 0.41 & $(-1.57$ to 2.39$)$ & 0.12 & & 0.08 & $(-4.55$ to 4.71$)$ & 0.73 \\
\hline Permission to watch TV & & -0.22 & $(-10.53$ to 10.09$)$ & 0.38 & & -0.22 & $(-12.88$ to 12.44$)$ & 0.37 \\
\hline Being consistent about TV & & 0.50 & $(-8.66$ to 9.66$)$ & 0.31 & & -0.08 & $(-8.19$ to 8.04$)$ & 0.72 \\
\hline Being consistent about games & & -1.62 & $(-11.08$ to 7.83$)$ & 0.02 & & -0.32 & $(-5.68$ to 5.04$)$ & 0.19 \\
\hline Monitoring of TV & & -0.33 & $(-2.80$ to 2.14$)$ & 0.21 & & 0.04 & $(-4.42$ to 4.50$)$ & 0.87 \\
\hline Modelling for games & & -0.70 & $(-4.66$ to 3.26$)$ & 0.03 & & -0.33 & $(-3.75$ to 3.10$)$ & 0.20 \\
\hline $\begin{array}{l}\text { Letting your child choose him/ } \\
\text { herself how long he/she can play } \\
\text { games }\end{array}$ & & -0.51 & $(-6.21$ to 5.20$)$ & 0.10 & & 0.39 & $(-6.65$ to 7.42$)$ & 0.20 \\
\hline SE for monitoring TV & & -0.04 & $(-4.54$ to 4.46$)$ & 0.90 & & 0.16 & ( -3.95 to 4.27$)$ & 0.48 \\
\hline SE for motivating games & & 0.31 & $(-3.29$ to 3.91$)$ & 0.40 & & -0.24 & ( -4.69 to 4.20$)$ & 0.37 \\
\hline
\end{tabular}

\begin{tabular}{|c|c|c|c|c|c|c|c|c|}
\hline & \multicolumn{4}{|c|}{ Low SES } & \multicolumn{4}{|c|}{ Medium-high SES } \\
\hline & $\overline{\mathbf{N}}$ & Adjusted $\mathbf{R}^{2}$ & $\mathbf{F}$ & p Value & $\overline{\mathbf{N}}$ & Adjusted $\mathbf{R}^{2}$ & $\mathbf{F}$ & p Value \\
\hline \multicolumn{9}{|c|}{ Outcome variable: physical activity (minutes/day) } \\
\hline \multirow[t]{2}{*}{ Full model } & 28 & 0.244 & 0.471 & 0.887 & 141 & 0.206 & 4.625 & $<0.001$ \\
\hline & & $\boldsymbol{\beta}$ & $95 \% \mathrm{Cl}$ & p Value & & $\boldsymbol{\beta}$ & $95 \% \mathrm{Cl}$ & p Value \\
\hline \multicolumn{9}{|l|}{ Explanatory variables } \\
\hline BMI of mother & & 0.05 & $(-0.36$ to 47$)$ & 0.83 & & -0.01 & $(-0.23$ to 21$)$ & 0.93 \\
\hline BMI of father & & 0.19 & $(-0.44$ to 82$)$ & 0.51 & & -0.01 & $(-0.29$ to 26$)$ & 0.88 \\
\hline Child's age & & 0.09 & $(-1.42$ to 1.60$)$ & 0.73 & & 0.14 & $(-0.39$ to 67$)$ & 0.08 \\
\hline Child's gender & & 0.08 & $(-4.76$ to 4.91$)$ & 0.77 & & 0.10 & $(-1.50$ to 4.70$)$ & 0.21 \\
\hline Availability of sports equipment & & 0.03 & $(-1.77$ to 1.82$)$ & 0.92 & & 0.20 & $(-0.61$ to 1.00$)$ & 0.02 \\
\hline SE for monitoring PA & & -0.07 & (-2.42 to 2.28$)$ & 0.83 & & 0.12 & $(-0.69$ to 93$)$ & 0.16 \\
\hline SE for modelling PA & & -0.33 & $(-2.80$ to 2.15$)$ & 0.41 & & 0.21 & $(-0.49$ to 91$)$ & 0.03 \\
\hline SE for motivating PA & & 0.49 & $(-2.43$ to 3.42$)$ & 0.15 & & 0.15 & $(-0.74$ to 1.03$)$ & 0.11 \\
\hline SE for giving PA choice & & -0.06 & $(-3.54$ to 3.41$)$ & 0.82 & & 0.07 & $(-0.92$ to 1.06$)$ & 0.39 \\
\hline \multirow[t]{3}{*}{ SE for involving PA } & & -0.03 & $(-2.05$ to 1.98$)$ & 0.91 & & 0.01 & $(-0.77$ to 79$)$ & 0.92 \\
\hline & \multicolumn{4}{|c|}{ Younger children (6-8 years) } & \multicolumn{4}{|c|}{ Older children (9-12 years) } \\
\hline & $\overline{\mathbf{N}}$ & Adjusted $\mathbf{R}^{2}$ & $\mathbf{F}$ & p Value & $\overline{\mathbf{N}}$ & Adjusted $\mathbf{R}^{2}$ & $\mathbf{F}$ & p Value \\
\hline \multicolumn{9}{|c|}{ Outcome variable: physical activity (minutes/day) } \\
\hline Full model & 57 & 0.189 & 2.304 & 0.027 & 111 & 0.060 & 1.696 & 0.092 \\
\hline
\end{tabular}


Table 3 Continued

\begin{tabular}{|c|c|c|c|c|c|c|c|c|}
\hline & \multicolumn{4}{|c|}{ Younger children (6-8 years) } & \multicolumn{4}{|c|}{ Older children (9-12 years) } \\
\hline & $\overline{\mathbf{N}}$ & Adjusted $\mathrm{R}^{2}$ & $\mathrm{~F}$ & p Value & $\overline{\mathbf{N}}$ & Adjusted $\mathrm{R}^{2}$ & $\mathbf{F}$ & $p$ Value \\
\hline & & $\boldsymbol{\beta}$ & $95 \% \mathrm{Cl}$ & p Value & & $\beta$ & $95 \% \mathrm{Cl}$ & p Value \\
\hline \multicolumn{9}{|l|}{ Explanatory variables } \\
\hline Family SES & & -0.04 & $(-0.85$ to 78$)$ & 0.80 & & -0.14 & $(-0.84$ to 55$)$ & 0.16 \\
\hline $\mathrm{BMI}$ of mother & & 0.06 & $(-0.22$ to 34$)$ & 0.62 & & -0.04 & $(-0.29$ to 33$)$ & 0.74 \\
\hline BMI of father & & 0.19 & $(-0.22$ to 60$)$ & 0.16 & & -0.08 & $(-0.38$ to 22$)$ & 0.43 \\
\hline Child's gender & & 0.08 & $(-2.34$ to 2.50$)$ & 0.53 & & 0.10 & $(-1.80$ to 2.00$)$ & 0.30 \\
\hline Availability of sports equipment & & 0.08 & $(-1.00$ to 1.15$)$ & 0.55 & & 0.17 & $(-0.67$ to 1.00$)$ & 0.09 \\
\hline SE for monitoring PA & & 0.09 & $(-1.05$ to 1.23$)$ & 0.54 & & 0.09 & $(-0.94$ to 1.12$)$ & 0.39 \\
\hline SE for modelling PA & & 0.08 & $(-0.93$ to 1.09$)$ & 0.59 & & 0.22 & $(-0.64$ to 1.07$)$ & 0.07 \\
\hline SE for motivating PA & & 0.40 & $(-0.85$ to 1.65$)$ & 0.02 & & 0.07 & $(-1.07$ to 1.20$)$ & 0.56 \\
\hline SE for giving PA choice & & 0.10 & $(-1.29$ to 1.49$)$ & 0.49 & & 0.06 & $(-1.29$ to 1.42$)$ & 0.54 \\
\hline SE for involving PA & & 0.02 & $(-1.39$ to 1.44$)$ & 0.90 & & -0.07 & $(-0.96$ to 83$)$ & 0.58 \\
\hline
\end{tabular}

\begin{tabular}{|c|c|c|c|c|c|c|c|c|}
\hline & \multicolumn{4}{|c|}{ Girls } & \multicolumn{4}{|c|}{ Boys } \\
\hline & & Adjusted & & & & Adjusted & & \\
\hline & $\mathbf{N}$ & $\mathbf{R}^{2}$ & $\mathbf{F}$ & p Value & $\mathbf{N}$ & & $\mathbf{F}$ & p Value \\
\hline \multicolumn{9}{|c|}{ Outcome variable: physical activity (minutes/day) } \\
\hline \multirow[t]{2}{*}{ Full model } & 86 & 0.253 & 3.880 & $<0.001$ & 84 & 0.048 & 1.419 & 0.189 \\
\hline & & $\boldsymbol{\beta}$ & $95 \% \mathrm{Cl}$ & p Value & & $\boldsymbol{\beta}$ & $95 \% \mathrm{Cl}$ & p Value \\
\hline \multicolumn{9}{|l|}{ Explanatory variables } \\
\hline Family SES & & -0.03 & $(-0.78$ to 73$)$ & 0.82 & & -0.11 & $(-0.84$ to 62$)$ & 0.35 \\
\hline $\mathrm{BMI}$ of mother & & 0.06 & $(-0.18$ to 30$)$ & 0.58 & & -0.01 & $(-0.30$ to 28$)$ & 0.94 \\
\hline BMI of father & & 0.14 & $(-0.20$ to 48$)$ & 0.19 & & -0.16 & $(-0.50$ to 19$)$ & 0.19 \\
\hline Child's age & & 0.11 & $(-0.50$ to 71$)$ & 0.29 & & 0.21 & $(-0.60$ to 1.02$)$ & 0.09 \\
\hline $\begin{array}{l}\text { Availability of sports } \\
\text { equipment }\end{array}$ & & 0.20 & $(-0.57$ to 98$)$ & 0.05 & & 0.04 & $(-1.12$ to 1.19$)$ & 0.76 \\
\hline SE for monitoring PA & & 0.04 & $(-1.04$ to 1.12$)$ & 0.77 & & 0.08 & $(-1.07$ to 1.22$)$ & 0.54 \\
\hline SE for modelling PA & & 0.26 & $(-0.55$ to 1.07$)$ & 0.02 & & -0.02 & $(-125$ to 1.22$)$ & 0.93 \\
\hline SE for motivating PA & & 0.27 & $(-0.90$ to 1.43$)$ & 0.04 & & 0.06 & $(-1.15$ to 1.28$)$ & 0.62 \\
\hline SE for giving PA choice & & 0.07 & $(-1.16$ to 1.30$)$ & 0.51 & & 0.14 & $(-1.36$ to 1.63$)$ & 0.26 \\
\hline SE for involving PA & & 0.04 & $(-0.89$ to 97$)$ & 0.74 & & 0.08 & $(-1.28$ to 1.45$)$ & 0.65 \\
\hline \multicolumn{9}{|c|}{ Outcome variable: screen time (minutes/day) } \\
\hline Full model & 23 & 0.450 & 2.285 & 0.121 & 27 & 0.688 & 5.095 & 0.004 \\
\hline \multicolumn{9}{|l|}{ Explanatory variables } \\
\hline Family SES & & -0.35 & $(-2.54$ to 1.83$)$ & 0.14 & & -0.14 & $(-1.69$ to 1.42$)$ & 0.35 \\
\hline $\mathrm{BMI}$ of mother & & 0.38 & $(-0.37$ to 1.13$)$ & 0.18 & & -0.27 & $(-1.24$ to 70$)$ & 0.25 \\
\hline BMI of father & & -0.06 & $(-1.04$ to 92$)$ & 0.79 & & 0.16 & $(-0.70$ to 1.02$)$ & 0.35 \\
\hline Child's age & & -0.02 & $(-2.19$ to 2.16$)$ & 0.94 & & -0.35 & $(-2.54$ to 1.84$)$ & 0.10 \\
\hline Availability of TV & & -0.29 & $(-7.67$ to 7.09$)$ & 0.23 & & -0.14 & (-4.61 to 4.33$)$ & 0.54 \\
\hline Availability of game consoles & & 0.22 & $(-2.50$ to 2.94$)$ & 0.32 & & 0.22 & $(-2.32$ to 2.75$)$ & 0.21 \\
\hline Permission to watch TV & & -0.21 & $(-11.77$ to 11.36$)$ & 0.46 & & -0.60 & $(-16.35$ to 15.16$)$ & 0.03 \\
\hline Being consistent about TV & & 0.39 & $(-18.43$ to 19.20$)$ & 0.47 & & -0.21 & $(-4.89$ to 4.47$)$ & 0.19 \\
\hline $\begin{array}{l}\text { Being consistent about } \\
\text { games }\end{array}$ & & -0.21 & $(-10.92$ to 10.50$)$ & 0.54 & & -0.83 & $(-5.71$ to 4.05$)$ & 0.01 \\
\hline Monitoring of TV & & -0.39 & $(-6.86$ to 6.07$)$ & 0.43 & & -0.16 & $(-2.68$ to 2.37$)$ & 0.30 \\
\hline Modelling for games & & 0.10 & $(-3.51$ to 3.70$)$ & 0.74 & & -0.45 & $(-2.83$ to 1.93$)$ & 0.01 \\
\hline $\begin{array}{l}\text { Permissiveness how long } \\
\text { games }\end{array}$ & & 0.54 & $(-5.84$ to 6.98$)$ & 0.12 & & -0.26 & $(-5.02$ to 4.50$)$ & 0.11 \\
\hline SE for monitoring TV & & 0.02 & $(-3.98$ to 3.95$)$ & 0.93 & & -0.17 & $(-4.19$ to 3.84$)$ & 0.32 \\
\hline SE for motivating games & & -0.37 & $(-3.75$ to 3.00$)$ & 0.13 & & 0.32 & $(-3.50$ to 4.15$)$ & 0.26 \\
\hline
\end{tabular}

Although these three parenting-related factors were associated with PA or screen time in children in the total sample, it has to be acknowledged that many specific parenting practices did not significantly influence children's PA or screen-time behaviour when they were entered into the multivariable model. Although this is similar to a previous study of van Sluijs $e t a l,{ }^{44}$ which also found many single but only a few multivariable 
associations between correlates and children's behaviour, our results were in contrast to what we expected. Dividing more general parenting practices into very concrete specific parenting practices and investigating the parental self-efficacy related to each specific parenting practice were thought to be of extra value in identifying parental correlates of PA and screen time in children. Nevertheless, the stratified analyses revealed that several parenting practices and related self-efficacy were only significantly related to children's PA and screen-time behaviour in specific subgroups. Regarding parental BMI and family SES, only significant association between specific parenting practices and related self-efficacy and PA and screen time were found in normal weight families and families with a medium-high SES. These findings suggest that more research is needed to discover other parenting-related factors to increase PA and reduce screen time in at-risk families (high BMI and low SES).

Child's age seemed to be a significant influencing factor in the associations between parental self-efficacy for motivating your child to be physically active and PA in younger children. Only borderline significant effects were found in older children. Also, the literature shows that parental control begins to fade as the child grows up and that older primary schoolchildren (9-12 years) get more freedom and decision-making power of their parents. ${ }^{45}$ Furthermore, previous research examining associations between parenting practices and related selfefficacy and children's diet showed that associations were only significant for younger children (6-8 years old; De Lepeleere S, Verloigne M, Cardon G and De Bourdeaudhuij I, submitted).

Finally, gender seemed to be an important influencing factor in the relationship between parenting practices and parental self-efficacy with PA and screen time. For PA, girls were more physically active when parents did not find it difficult to be physically active themselves and to motivate their child to be physically active, whereas for screen time boys had a lower screen time if parents let their child ask for permission to watch TV, if parents followed up their rules about gaming and if they limited their own gaming. Therefore, this study's results could suggest that future interventions might focus on different parenting strategies when targeting different groups of families to increase children's PA and limit children's screen time. This finding is very important for future intervention developers to not make one general intervention for all parents but to tailor interventions to subgroups. ${ }^{46}$

\section{Strengths and limitations}

The main strength of this study is the presentation of valuable and unique research data since it examined associations of both specific parenting practices and related parental self-efficacy with children's PA and screen time. For every specific parenting practice, a related parental self-efficacy was defined which gives more insight into parental correlates of children's PA and screen time compared with the more general formulated parenting practices. To the best of our knowledge, parental self-efficacy related to specific parenting practices has only been investigated in one study. ${ }^{27}$ Furthermore, analyses were conducted to study if associations between specific parenting practices and related parental self-efficacy and children's PA and screen-time behaviour differed for specific subgroups. This information could be important for future intervention developers to tailor the intervention to a specific subgroup.

However, this study was also subjected to some limitations. First, the self-report questionnaires may have led to inconsistency with actual experiences or social desirability bias. Second, both PA and screen time were assessed by adding up minutes spent in different behaviours (PA: active transportation and time spent in sports; screen time: time spent watching TV, playing computer games and using game consoles for both weekend and weekdays). Consequently, the association of the parenting-related factors with the different behaviours as such was not investigated. Another limitation of this study is that the screen-time measure did not include smartphone use. Currently, the use of smartphones in primary schoolchildren in Flanders is still limited, ${ }^{47}$ but the evolving nature of screen-time behaviours suggests that future studies could also include it as part of the screen-time behaviour, even in a primary school age group. Fourth, interval scales were used to measure specific parenting practices and related parental self-efficacy. Therefore, the absolute magnitudes of these variables cannot be provided. Next, since this study was a cross-sectional study, it was not possible to make statements about causality. Furthermore, since the number of participants in the stratified analyses for screen time with family SES and child's age was too small, it was not relevant to investigate these associations separately. Finally, $88 \%$ of participants were female and $84 \%$ of participating parents had a medium-high SES, which may have contributed to a certain amount of selection bias. Therefore, we should be cautious about generalising our findings to all parents of primary schoolchildren.

\section{CONCLUSIONS}

This study is unique since it investigated the association between very specific parenting practices as well as related parental self-efficacy and primary schoolchildren's PA and screen time, which is an understudied subject. In contrast to what we expected, the findings of this study showed that only a very few specific parenting practices and related parental self-efficacy were associated with children's PA and screen time, although more significant associations were found within specific subgroups. More experimental (ie, effect evaluation studies of family-focused interventions targeting PA and screen time of primary schoolchildren) and longitudinal 
studies are needed to provide evidence for predictive associations between parenting-related factors and children's PA and screen time.

Acknowledgements The authors wish to thank the participating schools, their students and the parents of the students.

Contributors SDL, MV, GC and IDB developed the information flyers and the online questionnaire. Furthermore, SDL and MV conducted the Single and Multiple Linear Regression and Moderated Regression analyses. SDL drafted the manuscript. All authors revised the article critically for important intellectual content and approved the final manuscript.

Funding This work was supported by the Flemish Agency for Care and Health (B/12 732/01); and the Research Foundation Flanders (FWO) (FW014/ASP/ 066, FW013/PD0/191).

Competing interests None declared.

Patient consent Obtained.

Ethics approval Ethics Committee of the Ghent University Hospital.

Provenance and peer review Not commissioned; externally peer reviewed.

Data sharing statement Technical appendix, statistical code and data set available from the corresponding author at Ghent University, who will provide a permanent, citable and open access home for the data set.

Open Access This is an Open Access article distributed in accordance with the Creative Commons Attribution Non Commercial (CC BY-NC 4.0) license, which permits others to distribute, remix, adapt, build upon this work noncommercially, and license their derivative works on different terms, provided the original work is properly cited and the use is non-commercial. See: http:// creativecommons.org/licenses/by-nc/4.0/

\section{REFERENCES}

1. James J, Kerr D. Prevention of childhood obesity by reducing soft drinks. Int J Obes (Lond) 2005;29(Suppl 2):S54-7.

2. Moreno LA, Rodriguez G. Dietary risk factors for development of childhood obesity. Curr Opin Clin Nutr Metab Care 2007;10:336-41.

3. Carrel AL, Clark RR, Peterson SE, et al. Improvement of fitness, body composition, and insulin sensitivity in overweight children in a school-based exercise program: a randomized, controlled study. Arch Pediatr Adolesc Med 2005;159:963-8.

4. Gortmaker SL, Peterson K, Wiecha J, et al. Reducing obesity via a school-based interdisciplinary intervention among youth: Planet Health. Arch Pediatr Adolesc Med 1999;153:409-18.

5. Robinson TN. Reducing children's television viewing to prevent obesity: a randomized controlled trial. JAMA 1999;282:1561-7.

6. Riddoch CJ, Bo AL, Wedderkopp N, et al. Physical activity levels and patterns of 9- and 15-yr-old European children. Med Sci Sports Exerc 2004;36:86-92.

7. van Sluijs EM, Skidmore PM, Mwanza K, et al. Physical activity and dietary behaviour in a population-based sample of British 10-year old children: the SPEEDY study (Sport, Physical activity and Eating behaviour: environmental Determinants in Young people). BMC Public Health 2008;8:388.

8. Troiano RP, Berrigan D, Dodd KW, et al. Physical activity in the United States measured by accelerometer. Med Sci Sports Exerc 2008;40:181-8.

9. Verloigne M, Van LW, Maes L, et al. Levels of physical activity and sedentary time among 10- to 12-year-old boys and girls across 5 European countries using accelerometers: an observational study within the ENERGY-project. Int J Behav Nutr Phys Act 2012;9:34.

10. Tremblay MS, LeBlanc AG, Kho ME, et al. Systematic review of sedentary behaviour and health indicators in school-aged children and youth. Int J Behav Nutr Phys Act 2011;8:98.

11. Brug J, van Stralen MM, Te Velde SJ, et al. Differences in weight status and energy-balance related behaviors among schoolchildren across Europe: the ENERGY-project. PLOS ONE 2012;7:e34742.

12. Trost $S G$, Loprinzi PD. Parental influences on physical activity behavior in children and adolescents: a brief review. Am J Lifestyle Med 2011;5:171-81.
13. Beets MW, Cardinal BJ, Alderman BL. Parental social support and the physical activity-related behaviors of youth: a review. Health Educ Behav 2010;37:621-44.

14. Edwardson CL, Gorely T. Activity-related parenting practices and children's objectively measured physical activity. Pediatr Exerc Sci 2010;22:105-13.

15. Gustafson SL, Rhodes RE. Parental correlates of physical activity in children and early adolescents. Sports Med 2006;36:79-97.

16. Trost SG, Sallis JF, Pate RR, et al. Evaluating a model of parental influence on youth physical activity. Am J Prev Med 2003;25:277-82.

17. Lindsay AC, Sussner KM, Kim J, et al. The role of parents in preventing childhood obesity. Future Child 2006;16:169-86.

18. Campbell K, Hesketh K, Crawford D, et al. The Infant Feeding Activity and Nutrition Trial (INFANT) an early intervention to prevent childhood obesity: cluster-randomised controlled trial. BMC Public Health 2008;8:103.

19. Gerards SM, Sleddens EF, Dagnelie PC, et al. Interventions addressing general parenting to prevent or treat childhood obesity. Int J Pediatr Obes 2011;6:e28-45.

20. Jago R, Davison KK, Brockman R, et al. Parenting styles, parenting practices, and physical activity in 10- to 11-year olds. Prev Med 2011;52:44-7.

21. Verloigne $\mathrm{M}$, Van Lippevelde $\mathrm{W}$, Maes L, et al. Family- and school-based correlates of energy balance-related behaviours in 10-12-year-old children: a systematic review within the ENERGY (EuropeaN Energy balance Research to prevent excessive weight Gain among Youth) project. Public Health Nutr 2012;15:1380-95.

22. Kaplan JP, Liverman CT, Kraak VI. Preventing childhood obesity: health in the balance. Washington: National Academies Press, 2004

23. De Lepeleere S, DeSmet A, Verloigne $\mathrm{M}$, et al. What practices do parents perceive as effective or ineffective in promoting a healthy diet, physical activity, and less sitting in children: parent focus groups. BMC Public Health 2013;13:1067.

24. Jones TL, Prinz RJ. Potential roles of parental self-efficacy in parent and child adjustment: a review. Clin Psychol Rev 2005;25:341-63.

25. Jago R, Edwards MJ, Urbanski CR, et al. General and specific approaches to media parenting: a systematic review of current measures, associations with screen-viewing, and measurement implications. Child Obes 2013;9(Suppl):S51-72.

26. Trost SG, McDonald S, Cohen A. Measurement of general and specific approaches to physical activity parenting: a systematic review. Child Obes 2013;9(Suppl):S40-50.

27. Jago R, Sebire SJ, Edwards MJ, et al. Parental TV viewing, parental self-efficacy, media equipment and TV viewing among preschool children. Eur J Pediatr 2013;172:1543-5.

28. Duke RE, Bryson S, Hammer LD, et al. The relationship between parental factors at infancy and parent-reported control over children's eating at age 7. Appetite 2004;43:247-52

29. Cullen KW, Baranowski T, Owens E, et al. Availability, accessibility, and preferences for fruit, $100 \%$ fruit juice, and vegetables influence children's dietary behavior. Health Educ Behav 2003;30:615-26.

30. Blissett J, Haycraft E. Are parenting style and controlling feeding practices related? Appetite 2008;50:477-85.

31. Reynolds KD, Hinton AW, Shewchuk RM, et al. Social cognitive model of fruit and vegetable consumption in elementary school children. J Nutr Educ 1999;31:23-30.

32. Garcia F, Gracia E. Is always authoritative the optimum parenting style? Evidence from Spanish families. Adolescence 2009;44:101-31.

33. Papaioannou MA, Cross MB, Power TG, et al. Feeding style differences in food parenting practices associated with fruit and vegetable intake in children from low-income families. J Nutr Educ Behav 2013;45:643-51.

34. Wagner A, Klein-Platat C, Arveiler D, et al. Parent-child physical activity relationships in 12-year old French students do not depend on family socioeconomic status. Diabetes Metab 2004;30:359-66.

35. Winkleby MA, Jatulis DE, Frank E, et al. Socioeconomic status and health: how education, income, and occupation contribute to risk factors for cardiovascular disease. Am J Public Health 1992;82:816-20.

36. [No authors listed]. Physical status: the use and interpretation of anthropometry. Report of a WHO Expert Committee. World Health Organ Tech Rep Ser 1995;854:1-452.

37. Deforche B, De Bourdeaudhuij I, D'hondt E, et al. Objectively measured physical activity, physical activity related personality and body mass index in 6- to 10-yr-old children: a cross-sectional study. Int J Behav Nutr Phys Act 2009;6:25.

38. Philippaerts RM, Matton L, Wijndaele $\mathrm{K}$, et al. Validity of a physical activity computer questionnaire in 12- to 18-year-old boys and girls. Int J Sports Med 2006;27:131-6. 
39. Larios SE, Ayala GX, Arredondo EM, et al. Development and validation of a scale to measure Latino parenting strategies related to children's obesogenic behaviors. The parenting strategies for eating and activity scale (PEAS). Appetite 2009;52:166-72

40. Sherwood NE, Taylor WC, Treuth M, et al. Measurement characteristics of activity-related psychosocial measures in 8- to 10-year-old African-American girls in the Girls Health Enrichment Multisite Study (GEMS). Prev Med 2004;38(Suppl):S60-68.

41. Decker JW. Initial development and testing of a questionnaire of parental self-efficacy for enacting healthy lifestyles in their children. $J$ Spec Pediatr Nurs 2012;17:147-58.

42. Crespo NC, Elder JP, Ayala GX, et al. Results of a multi-level intervention to prevent and control childhood obesity among Latino children: the Aventuras Para Ninos Study. Ann Behav Med 2012;43:84-100.
43. Vik FN, Lien N, Berntsen S, et al. Evaluation of the UP4FUN intervention: a cluster randomized trial to reduce and break up sitting time in European 10-12-year-old children. PLOS ONE 2015;10: e0122612.

44. van Sluijs EM, Page A, Ommundsen $\mathrm{Y}$, et al. Behavioural and social correlates of sedentary time in young people. Br J Sports Med 2010;44:747-55.

45. Roberts BP, Blinkhorn AS, Duxbury JT. The power of children over adults when obtaining sweet snacks. Int J Paediatr Dent 2003;13:76-84

46. Noar SM, Benac CN, Harris MS. Does tailoring matter? Metaanalytic review of tailored print health behavior change interventions. Psychol Bull 2007;133:673-93.

47. Zarouali B, De Pauw P, Walrave M, et al. Mediabezit en -gebruik bij minderjarigen. Een rapport in het kader van het AdLit onderzoeksproject. Document beschikbaar op. 2015. http://www. AdLit.be 